\title{
Serious Games for the Cognitive Stimulation of Adults: A Proposal of a Pilot Project
}

\author{
Ricardo Alves $^{1(\varpi)}$, Teresa Souto ${ }^{2}$, Paula Escudeiro ${ }^{1,3}$, and Nuno Escudeiro ${ }^{3,4}$ \\ ${ }^{1}$ Games Interaction and Learning Technoogies - GILT, Porto, Portugal \\ ricalves03@gmail.com, pmo@isep.ipp.pt \\ ${ }^{2}$ Faculty of Psychology, Education and Sports, \\ Lusófona University of Porto, Porto, Portugal \\ p2683@ulp.pt \\ ${ }^{3}$ Instituto Superior de Engenharia do Porto, Porto, Portugal \\ nfelisep.ipp.pt \\ ${ }^{4}$ Laboratory of Artificial Intelligence and Decision Support, \\ INESC TEC, Porto, Portugal
}

\begin{abstract}
One of the major challenges for healthcare professionals in the XXI century is the increasing number of elderly in the world population. It is clearly important to find ways to stimulate cognitively this population, helping them to develop strategies and maintaining independency in their daily life activities. Conventional cognitive stimulation is time consuming task often causing discomfort in patients. Computer based tools may be used to perform cognitive stimulation and improve transferability in a setting that does not increase anxiety in individuals. This paper aims to present a pilot study of automatic platforms to enhance the cognitive process for older adults in order to promote an active aging.
\end{abstract}

Keywords: Pilot project - Virtual reality - Serious games · Active ageing · Cognitive processes

\section{Introduction}

It is anticipated that the number of individuals among the worldwide population, over the age of 60 "is expected to more than double, from 841 million people in 2013 to more than 2 billion in 2050" [1]. The increasing number of the elderly population is one of main challenges of the XXI century, being of utmost importance to invest in the field of aging, understanding how healthcare professionals can intervene, promoting an active ageing as an indispensable component to minimize the social and economic impact of this phenomenon. Active ageing is "the process of optimizing opportunities for health, participation and security in order to enhance quality of life as people age" [2]. Since aging is accompanied by changes in cognitive functioning in several areas [3], it is clearly important to find ways to stimulate cognitively this population, helping them to develop compensation strategies and maintaining independency in their daily life activities [4].

Automatic tools, based on computer technology, notably serious games, are becoming more common to support the assessment and intervention in cognitive 
processes. Serious games may simulate daily life scenarios where the user active role is designed to promote generalization and transferability thus, contributing to active aging.

In this paper we propose a serious game for dynamically monitoring the patient's cognitive abilities and adapting the game activities to the user specific needs.

In the remaining of this paper we review the state of the art in Sect. 2. In Sect. 3 we describe the proposed serious game and the evaluation methodology and in Sect. 4 we conclude.

\section{Automatic Platforms}

In recent years we have seen an increase attempt to identify ways to reduce and/or neutralize the progression of neurocognitive decline. This trend is largely based on the idea of cognitive plasticity [5]. Accordingly, cognitive stimulation, is being used to slow down cognitive decline, by reinforcing the functions relatively preserved [6,7], using intervention programs [8], allowing the brain to change its structures and functions [9].

\subsection{Applicability and Potential}

The use of an automatic platform with guiding principles that supports both evaluative and psychoeducational approaches, as well as a programmed neurocognitive stimulation, based on an emerging methodology of stimuli presentation, the Serious Games (SG), is of utmost importance. SG are a generally accepted software interface created with the purpose of helping in the assessment and intervention, other than entertainment [10], that has been increasingly presented as an important resource for assessment and intervention in cognitive processes [10-13].

Conventional cognitive assessment is based on neuropsychological evaluation that is time consuming, expensive [14], and often causing embarrassment and discomfort in patients [15]. Being so, the use of new technologies as a procedure to assess cognitive function and functional deficits in this population [16] means developing tools aimed at reducing the cost and time associated with conventional methods [14] and also the introduction of a motivating element in interventions for this subjects [17].

The consolidation and expansion of this resource in multiple domains of human reality allowed important changes from education to intervention or training skills, as well as advances in new technologies targeted to improve life quality of individuals with special needs [12]. The resource to SG using Virtual Reality (VR) represents a scientific and technological development, and an important search for interactive interfaces that are closest to human senses. The VR ability to create dynamic and stimulating environments, aiming recovery of cognitive functions in which all behavioral responses can be registered, provides testing and training options otherwise impossible through traditional psychological methods [18]. 


\subsection{Application in the Therapeutic Area}

As a methodological resource, VR has a significant potential for cognitive evaluation and intervention in individuals with a diagnosis of incapacitating mental illness. VR facilitates access to stimulating exercises and tasks aimed at different skills (cognitive, motor) supported in virtual environments (VE) promoting significant association with individual's daily life tasks.

The potential of VE have been explored, highlighting the dynamic and motivational features that apply to recovery of cognitive functions, enables a methodical and exhaustive behavioral recording that represents a qualitatively improved alternative compared to traditional methodologies. Providing a flexible and controlled environment, VE are suitable to the use of multi-sensory channels, to be applied in experimental and therapeutic contexts [18].

The potential of this technology comes from its main features, including the possibility of user immersion in a perceptual world computer generated, i.e. the feeling of the subject that there is really (presence), the possibility of interaction with the environment in real time, giving the subject an active role and greater involvement by ensuring the ecological validity $[19,20]$. VE enable a specialized support in recovery process, as it promotes generalization of activities/tasks trained [21,22] and possibly catalysis the transference procedure [21-23].

\subsection{The Use of Serious Games with Older Adults}

The use of SG with older people is still in a premature phase [24]. However, previous studies show that SG will have an important impact in the prevention and rehabilitation of older people [25]. Multiple positive uses for VR previously described, and the empiric evidence that SG can be used with promising results in this population provides an incentive to pursue scientific research in this domain. SG can enhance through solving attractive tasks, the contexts needed for repeating tasks, feedback and background processing [25]. Despite a number of studies that point to difficulties regarding subjects getting familiar with the game technology [19], and problems interacting with SG [26], those difficulties derive from the fact that a majority of these SG were not created for this specific population. To overcome this problem, specific SG are emerging that follow specific guidelines especially suitable for older adults [10].

\section{Serious Games: A Pilot Project}

The pilot project is currently being developed at GILT (Games, Interaction and Learning Technologies) by a multidisciplinary team aiming the creation of an automatic platform for cognitive assessment and training that can be used to implement individualized interventions and respective assessment (taking into count the limitations of the subject and symptoms).

The platform methodological construction options consider, in the program, a complete evaluation procedure. To build the evaluation module, it is important to appeal for planned use of tools and methods, using the amendments that enable the project 
presentation on time and the evaluation module must also allow running a study on the relevance and effectiveness of the stimuli that will be carried out.

The program intervention must have a modular structure so it can promote generalization and transference to the individual's real life context, respecting one's rhythm and also creating interactions in a secure environment, where the user's anxiety levels will be minimized. Being so, it increases user's motivation and, at the same time, encourages task practice. The use of these interactive components enables the management and manipulation of different elements - stimuli setting, congruence among others. The user-specialist can structure and set modules to specific interventions. The program should also be able to keep track of the patient's cognitive abilities, to monitored goals/ purposes and to adapt the difficulty level of game to the user. Finally, be able to promote ecological interactions $[26,27]$ and facilitate the generalization and transference processes.

In this application, it will be required that no latencies or graphic inconsistencies occur and, simultaneously, that the three-dimensionality is congruently assured.

Several usability tests will be conducted, using multiple users. Their comments and remarks will be carefully registered. Experimental tests will be held to ensure the back office and application effectiveness.

Adjustments will be made during the test phase of the trial version of the application in order to blur the possible resistance in the use of the equipment and application. The devices will be chosen considering effectiveness, but also the perception of user's comfort.

In the final evaluation stage we will support the assessment of the cognitive function on several common scientific tests. We will use reference tests [28] such as WAIS-III, MoCA - Montreal Cognitive Assessment, STROOP, TMT - Trail Making Test, REY 15 Item Memory Test, California Verbal Learning Test.

\section{Conclusion}

If the beneficial effects of SG are demonstrated by robust studies, the potential social impact is huge considering: high prevalence of cognitive impairment and popularity of video games among future subjects in risk of cognitive decline. SG can be an attractive way and a sustainable method for improving or at least delay the neurocognitive decline, sensory-motor, psychosocial and emotional of the elderly [26]. After validated, platform for cognitive assessment and training can constitute a powerful screening tool for the early detection of cognitive impairment and the stored data can be collected, not only to estimate parameters that reflect cognitive processes, but also to monitor neuropsychological profiles and improve the intervention. 


\section{References}

1. United Nations. World Population Ageing 2013 [Internet]. Department of Economic and Social Affairs, Population Division, New York, USA. Report No.: ST/ESA/SER.A/348 (2013). http://www.un.org/en/development/desa/population/publications/pdf/ageing/ WorldPopulationAgeing2013.pdf

2. World Health Organization. Active Ageing: a Policy Framework. A Contribution of the World Health Organization to the Second United Nations World Assembly on Ageing, Madrid, Spain, April 2002. http://whqlibdoc.who.int/hq/2002/WHO_NMH_NPH_02.8.pdf

3. Glisky, E.: Changes in cognitive function in human aging. In: Riddle, D.R. (ed.) Brain Aging: Models, Methods, and Mechanisms. CRC Press, Boca Raton (2007)

4. American Psychiatric Association: Diagnostic and Statistical Manual of Mental Disorders, 5th edn. American Psychiatric Publishing, Arlington (2013)

5. Mayas, J., Parmentier, F., Andrés, P., Ballesteros, S.: Plasticity of attentional functions in older adults after non-action video game training: a randomized controlled trial. PLoS ONE 9(3), 1-11 (2014)

6. La Rue, A.: Healthy brain aging: role of cognitive reserve, cognitive stimulation and cognitive. Clin. Geriatr. Med. 26, 99-111 (2010). (A. K. Desai, Ed.)

7. Spector, A., Orrell, M., Woods, B.: Cognitive stimulation to improve cognitive functioning in people with dementia. Int. J. Geriatr. Psychiatry 25(12), 1253-1258 (2010)

8. Coltheart, M.: Assumptions and methods in cognitive neuropsychology. In: Rapp, B. (ed.) Handbook of Cognitive Neuropsychology: What Deficits Reveal About the Human Mind, pp. 3-21. Psychology Press, Philadelphia (2000)

9. Duffau, H.: Brain plasticity: from pathophysiological mechanisms to therapeutic applications. J. Clin. Neurosci. 13(9), 885-897 (2006)

10. Robert, P.H., König, A., Amieva, H., et al.: Recommendations for the use of serious games in people with Alzheimer's disease, related disorders and frailty. Front. Aging Neurosci. 6(54), 1-13 (2014). doi:10.3389/fnagi.2014.00054

11. Riva, G., Rizzo, A., Alpini, D., et al.: Virtual environments in the diagnosis, prevention and intervention of age-related diseases: a review of VR scenarios proposed in the EC VETERAN Project. Cyberpsychol Behav. 2, 577-591 (1999)

12. Rizzo, A., Wiederhold, M., Buckwalter, J.: Basic issues in the use of virtual environments for mental health application. In: Riva, G., Wiederhold, B.K., Molinari, E. (eds.) Virtual Environments in Clinical Psychology and Neuroscience, pp. 21-42. Ios Press, Amsterdam (1998)

13. Cherniack, E.P.: Not just fun and games: applications of virtual reality in the identification and rehabilitation of cognitive disorders of the elderly. Disabil. Rehabil. Assist. Technol. 6, 283-289 (2011). doi:10.3109/17483107.2010.542570

14. Zucchella, C., Sinforiani, E., Tassorelli, C., et al.: Serious games for screening pre-dementia conditions: from virtuality to reality? A pilot project. Funct. Neurol. 29(3), 153-158 (2014)

15. Segal, R., Bhatia, M., Drapeau, M.: Therapist's perception of benefits and costs of using virtual reality treatments. Cyberpsychology, Behav. Soc. Networking 14(1-2), 29-34 (2011)

16. Tarnanas, I., Tsolaki, M., Nef, T., et al.: Can a novel computerized cognitive screening test provide additional information for early detection of Alzheimer's disease? Alzheimers Dement. 10, 790-798 (2014). doi:10.1016/j.jalz.2014.01.002

17. Anguera, J.A., Boccanfuso, J., Rintoul, J.L., Al-Hashimi, et al.: Video game training enhances cognitive control in older adults. Nature 501, 97-102 (2013). doi:10.1038/nature12486 
18. Costa, R., Carvalho, L.: Experimentando um Ambiente Virtual com Pacientes Neuropsiquiátricos. II Conferência Internacional de Tecnologias de Informação e Comunicação na Educação - Challenges 2001, pp. 529-546, Braga (2001)

19. Rizzo, A.A., Kim, G.J.: A SWOT analysis of the field of VR rehabilitation and therapy. Presence Teleoper. Virtual Environ. 14, 119-146 (2005). doi:10.1162/1054746053967094

20. Dyck, M., Winbeck, M., Leiberg, S., et al.: Recognition profile of emotions in natural and virtual faces. PLoS ONE 3(11), e3268, 1-8 (2008)

21. Wendt, G.W.: Tecnologias de interface humano-computacional: realidade virtual e novos caminhos para pesquisa. Revista de Psiquiatria Clinica 38(5), 211-212 (2011)

22. Costa, R.: Ambientes Virtuais na Reabilitação Cognitiva de Pacientes Neurológicos e Psiquiátricos. UFRJ, Rio de Janeiro (2000)

23. Jerônimo, R.A., Lima, S.: Tecnologias Computacionais e ambientes virtuais no processo terapêutico de reabilitação. O mundo da Saúde 30(1), 96-106 (2006)

24. Alzheimer's Disease International: World Alzheimer Report 2014: Dementia and Risk Reduction: An Analysis of Protective and Modifiable Factors. Alzheimer's Disease International, London (2014)

25. Muscio, C., Tiraboschi, P., Guerra, U.P., et al.: Clinical trial design of serious gaming in mild cognitive impairment. Front. Aging Neurosci. 7(26), 1-6 (2015). doi:10.3389/fnagi. 2015.00026

26. Wiemeyer, J., Kliem, A.: Serious games in prevention and rehabilitation - a new panacea for elderly people? Eur. Rev. Aging Phys. Act. 9, 41-50 (2012). doi:10.1007/s11556-011-0093-x

27. Souto, T., Baptista, A., Tavares, D., et al.: Facial emotional recognition in schizophrenia: preliminary results of the virtual reality program for facial emotional recognition. Rev. Psiq. Clín. 40(4), 129-134 (2013)

28. Simões, M.R.: Instrumentos de avaliação psicológica de pessoas idosas: investigação e estudos de validação em Portugal. RIDEP 34(1), 9-33 (2012) 